\title{
GENÓTIPOS MELHORADOS DE MAMÃO (Carica papaya L.): AVALIAÇÃo TECNOLÓGICA DOS FRUTOS NA FORMA DE SORVETE ${ }^{1}$
}

\author{
Ligia R.R. SANTANA ${ }^{2, *}$, Fernando C.A.U. MATSUURA ${ }^{3}$, Ricardo L. CARDOSO ${ }^{4}$
}

\section{RESUMO}

O presente trabalho teve como objetivo a avaliação tecnológica na forma de sorvete, de frutos de cinco genótipos selecionados de mamão (CMF012, CMF020, CMF023, CMF031, CMF047), provenientes do Banco Ativo de Germoplasma da EMBRAPA Mandioca e Fruticultura, Cruz das Almas, Bahia. Estes genótipos foram identificados em estudos anteriores por apresentarem cor atraente, sabor agradável e valores elevados de sólidos solúveis ( ${ }^{\circ}$ Brix). As amostras de sorvete foram submetidas à avaliação sensorial para os atributos aparência, cor, aroma, sabor e textura, através de testes afetivos, utilizando-se escala hedônica estruturada de nove pontos. Realizou-

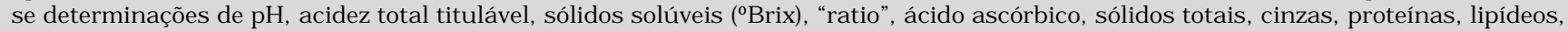
açúcares totais, redutores e não-redutores. Os resultados das avaliações sensoriais e físico-químicas foram analisados através de ANOVA e teste de Tukey. Os sorvetes demonstraram elevada aceitação, obtendo médias correspondentes ao conceito "gostei moderadamente" para todos os atributos avaliados. Os genótipos CMF020 e CMF031 destacaram-se alcançando média correspondente ao termo da escala hedônica "gostei muito" para o atributo sabor. Os provadores não indicaram prevalência entre os produtos quanto à aparência, cor e textura; portanto, os genótipos pouco atraentes como fruto de mesa, poderão ser aproveitados na indústria para elaboração de sorvete. Além disso, podem ser considerados como uma sobremesa valiosa e nutritiva, pois apresentaram niveis satisfatórios de carboidratos e razoáveis de vitamina $\mathrm{C}$ e proteinas. O estudo demonstrou que o sorvete de mamão é uma excelente alternativa para o aproveitamento da fruta.

Palavras-chave: Carica papaya L.; mamão; sorvete de mamão.

\section{SUMMARY}

IMPROVED GENOTYPES OF PAPAYA (Carica papaya L.): TECHNOLOGICAL EVALUATION AS ICE-CREAM. The objective of the present work was to evaluate as an alternative of consumption the ice-cream of five selective papaya genotypes (CMF012, CMF020, CMF023, CMF031, CMF047) obtained from the Active Germplasm Bank for Papaya at Embrapa Cassava and Fruit Crops, located in Cruz das Almas, Bahia State, Brazil. These genotypes were identified at before studies because they showed atractive colour, good flavour and highter soluble solid ( ${ }^{\circ}$ Brix). Sensory analyses of the ice-creams were carried out using affective tests (9 point hedonic scale) for the attributes of overall appearance, colour, odour, flavour and texture. The following physico-chemical determinations were carried out: $\mathrm{pH}$, total titrable acidity, soluble solid ( $\left.{ }^{\circ} \mathrm{Brix}\right)$, ratio, vitamin $\mathrm{C}$, total solid, ash, protein, lipid, total sugars, reducing and non-reducing sugars.The sensory and physico-chemical data were submitted to an analysis of variation, followed the Tukey test. The ice creams showed higher scores for all of attributes. The genotypes CMF020 and CMF031 were preferred in terms of flavour. The judges didn!t indicate preference among the products in terms of overall appearance, colour and texture, so the less atractive genotypes for the fresh fruit market, could be utilized for the industry to make ice cream. They are a nutritive dessert, because they showed enough carbohydrates, vitamin $\mathrm{C}$ and protein contents. This study showed that the papaya ice cream is an excellent alternative of consumption.

Keywords: Carica papaya L.; papaya; papaya ice-cream.

\section{1 - INTRODUÇÃO}

Os sorvetes são fabricados a partir de uma emulsão estabilizada, que através de processo tecnológico adequado, resulta num produto cremoso, suave e agradável ao paladar. As emulsões são compostas de água, produtos lácteos, gordura, açúcares, estabilizantes, emulsificantes e outros [14].

Os sorvetes devem ser considerados não como uma simples guloseima ou produto de verão, mas como uma sobremesa valiosa e nutritiva, que contribui com elementos muito importantes para uma alimentação equi-

\footnotetext{
${ }^{1}$ Recebido para publicação em 03/08/2002. Aceito para publicação em 08/09/2003 (000931).

${ }^{2}$ Departamento Ciências da Vida - Curso de Nutrição - UNEB, Estrada das Barreiras, s/n, Narandiba/Cabula, CEP 41195-001, Salvador-BA. E-mail: ligiarrs@bol.com.br

${ }^{3}$ Laboratório de Ciência e Tecnologia de Alimentos - Embrapa Mandioca e Fruticultura - CNPMF - CP 007, CEP44380-000, Cruz das Almas-BA. E-mail: fersaopaulo@zipmail.com.br

${ }^{4}$ Departamento de Química Agrícola e Solos - Escola de Agronomia UFBA, CEP 44380-000, Cruz das Almas-BA. E-mail: cardoso@ufba.br * A quem a correspondência deve ser enviada.
}

librada, tanto na infância como na idade adulta [15]. Por isso, os sorvetes constituem-se numa excelente alternativa à utilização da polpa de mamão, abrindose, desta forma, novas oportunidades para um produto manufaturado de mamão.

O mamão é rico em cálcio e carotenóides, o teor de ácido ascórbico atinge níveis consideráveis, sendo também elevados os níveis de açúcares nos frutos maduros [4]. Segundo BLEINROTH \& SIGRIST [4] a polpa de mamão é rica em $\mathrm{Fe}, \mathrm{Ca}, \mathrm{Mg}$ e $\mathrm{K}$.

O nível de ácidos orgânicos no mamão é notadamente baixo e a parte comestivel tem uma faixa de $\mathrm{pH}$ entre 4,5 a 6,0 [3]. DRAETTA et al. [8] em seus estudos com mamões da cultivar Comum amarela verificaram que o pH variou de 4,8 a 5,8 e uma cultivar do grupo Solo de 5,0 a 5,5.

Durante a fase de maturação ocorre um drástico aumento nos conteúdos de açúcares dos mamões [3]. DE MARTIN et al. [7] encontraram para o mamão da variedade Comum amarela os seguintes resultados: sólidos solúveis ( ${ }^{\circ}$ Brix)- 10,4; açúcares redutores (\%)- 7,97 e açúcares totais (\%)- 7,99. Em outro estudo, estes mes- 
mos autores [6] obtiveram os resultados: sólidos solúveis ( ${ }^{\circ}$ Brix)- 8,9; açúcares redutores (\%)- 6,58 e açúcares totais (\%)- 6,84. SOLER et al. [20] para a variedade Solo obtiveram os seguintes resultados: sólidos solúveis ( ${ }^{\circ}$ Brix)- 12,0; açúcares redutores (\%)- 10,75 e açúcares totais (\%)- 11,79.

DRAETTA et al. [8] verificaram que durante a maturação, o mamão Comum amarelo apresentou os seguintes resultados: na parte de cima dos frutos (próxima do pedúnculo), sólidos solúveis $\left({ }^{\circ} \mathrm{Brix}\right)-8,0$; açúcares redutores (\%)- 5,5 e açúcares totais (\%)- 6,0; na parte de baixo dos frutos, sólidos solúveis ( ${ }^{\circ}$ Brix)- 9,0; açúcares redutores (\%)- 6,9 e açúcares totais (\%)- 7,0. Concluíram que à medida em que o fruto foi amadurecendo, ocorreu aumento de sólidos solúveis ( ${ }^{\circ}$ Brix), açúcares totais e redutores.

A aparência vistosa e colorida dos mamões é o resultado da presença de pigmentos naturais nas células de seus tecidos. Dentre estes compostos coloridos destacam-se os carotenóides como os mais importantes [18].

O presente trabalho teve como objetivo avaliar, sob o aspecto tecnológico, frutos de cinco genótipos de mamão, na tentativa de identificar aqueles mais adequados ao processamento de sorvete. Estes genótipos foram selecionados de estudos anteriores, conduzidos em dois anos consecutivos, onde 12 genótipos melhorados de mamão, provenientes do Banco Ativo de Germoplasma da EMBRAPA-CNPMF, Cruz das Almas, Bahia, foram avaliados sob os aspectos sensorial e físico-químico [19]. Os frutos que apresentaram elevados valores de sólidos solúveis ("Brix) e "ratio", cor atraente e sabor agradável, foram indicados para o ensaio industrial na forma de sorvete, para se verificar o potencial de industrialização destes genótipos selecionados.

\section{2 - MATERIAL E MÉTODOS}

Os frutos foram colhidos de forma aleatória, quando estavam fisiologicamente desenvolvidos e apresentavam coloração da casca verde-claro com algumas estrias amarelas na região equatorial. Foram submetidos a uma lavagem em água com detergente, para remoção de sujidades na sua superfície externa, advindas do campo; em seguida, imersos em água clorada da rede pública. Os frutos foram colocados em caixas plásticas e armazenados em câmara com temperatura e umidade controladas $\left(22^{\circ} \mathrm{C}\right.$ e $\left.90 \%\right)$ para maturação uniforme [17]. Após 96 horas, aproximadamente, quando os frutos estavam com a coloração da casca $100 \%$ amarela, seguiram para a fase de processamento.

Trabalhou-se com frutos de cinco genótipos de mamão, sendo quatro genótipos do Grupo Formosa (CMF020, CMF023, CMF031, CMF047) e um híbrido entre o Grupo Solo e Formosa (CMF012).

Foram realizadas determinações físico-químicas na polpa do mamão maduro, que foi homogeneizada, obtendo-se quintuplicatas para a realização das análises. Para medida do $\mathrm{pH}$ foi utilizado um potenciômetro Coleman Mod.39 a $20^{\circ} \mathrm{C}$. Os valores de sólidos solú- veis ( ${ }^{\circ}$ Brix) foram tomados em refratômetro Carl Zeiss Mod.32-G a $20^{\circ} \mathrm{C}$. A acidez total titulável foi determinada de acordo com método no 22.038 e o ácido ascórbico através de titulometria pela reação com o corante 2,6diclorofenol indofenol, segundo o método no 43.056, ambos da A.O.A.C.[2]. O "ratio" foi calculado dividindose o valor de sólidos solúveis ( $\left.{ }^{\circ} \mathrm{Brix}\right)$ pelo valor da acidez total titulável. Os açúcares totais e redutores foram determinados pelo método $\mathrm{n}^{\circ} \mathbf{2 2} .038$ da A.O.A.C.[2], os açúcares não-redutores pela diferença entre açúcares totais e redutores. Sólidos totais determinados em aparelho OHAUS, modelo MB200 e cinzas por incineração a $550^{\circ} \mathrm{C}$ por duas horas, seguindo metodologia descrita nas normas do INSTITUTO ADOLFO LUTZ [11]

Para o processamento do sorvete, obteve-se primeiramente as metades de mamão através das etapas: lavagem dos frutos em água da rede pública (5pm), corte manual em duas partes, retirada das sementes e dos defeitos (manchas, porções batidas e necrosadas), descascamento manual, acondicionamento destas metades de polpa em sacos de polietileno, retirada do ar nas embalagens, congelamento em "freezer" a $-20^{\circ} \mathrm{C}$.

Foram realizados, preliminarmente, ensaios de formulação para o sorvete, na tentativa de padronizar os teores de açúcar, polpa de mamão e água do produto final. Utilizou-se a seguinte formulação final: açúcar (sacarose) - 15\%, leite em pó (integral) - 4\%, polpa de mamão - 50\%, água - 30\%, emulsificante (goma guar) 0,50\%, estabilizante (goma arábica) - 0,50\%.

O processamento foi realizado em linha semi-industrial, de acordo com o fluxograma da Figura 1.

Descongelamento da polpa de mama
$\downarrow$
Mistura dos ingredientes
$\downarrow$
Homogeneização
$\downarrow$
Maturação da mistura
$\downarrow$
Congelamento/Batimento
$\downarrow$
Enchimento das embalagens
$\downarrow$
Armazenamento

FIGURA 1. Fluxograma do processamento semi-industrial do sorvete de mamão.

Em um equipamento misturador da marca Poli modelo SX10, tipo liquidificador industrial, foi adicionado água e emulsificante, que ficaram sob agitação vigorosa durante 3 minutos; em seguida, juntou-se os ingredientes secos previamente misturados (açúcar, leite em pó e estabilizante). No mesmo equipamento, acrescentou-se a polpa de mamão descongelada à mistura, promovendo-se sua homogeneização por 3 minutos. A maturação consistiu em deixar a mistura em repouso à 
temperatura de $4^{\circ} \mathrm{C}$ durante 60 minutos, para que ocorresse a solidificação das gorduras e a viscosidade aumentasse devido à hidratação das proteínas do leite e absorção de água livre pelo estabilizante. O congelamento/batimento foi realizado em processadora descontínua da marca Inadal modelo MP, com capacidade de produção de 10 litros de sorvete por batelada. O congelamento ocorreu de forma rápida, sendo que o sorvete adquiriu a consistência semi-sólida adequada para o acondicionamento em 4 a 5 minutos, atingindo a temperatura de $-6^{\circ} \mathrm{C}$. Em seguida o sorvete foi colocado em vasilhames de polietileno e encaminhado ao "freezer", para que o restante da água se congelasse e ocorresse o seu endurecimento. O produto ficou armazenado em temperatura de $-20^{\circ} \mathrm{C}$.

O sorvete foi avaliado sensorialmente, através dos atributos aparência, cor, aroma, sabor e textura, utilizando-se escala hedônica estruturada de nove pontos ( 9 = gostei muitíssimo e 1 = desgostei muitíssimo) e uma equipe composta por 30 provadores [13,16, 21].

$\mathrm{Na}$ avaliação físico-química do sorvete, foram determinados os valores de $\mathrm{pH}$, sólidos solúveis ( $\left.{ }^{\circ} \mathrm{Brix}\right)$, acidez total titulável, "ratio", ácido ascórbico, cinzas, sólidos totais, açúcares totais, redutores e não-redutores seguindo a mesma metodologia utilizada nas determinações da matéria-prima. A quantidade de nitrogênio total nas amostras foi determinada pelo método de microKjedahl e multiplicada pelo fator 6,25, para obtenção da proteína total. O teor de lipídeo foi determinado em extrator Soxhlet completo, utilizando-se éter de petróleo para a extração. Umidade foi calculada do valor de sólidos totais subtraído de cem. Carboidratos foram obtidos pelo somatório dos valores das determinações de umidade, cinzas, proteína e lipídeos subtraído de cem.

Para a análise estatística, empregou-se o delineamento de blocos completos casualizados, com três repetições, para a avaliação sensorial e o delineamento inteiramente casualizado para a avaliação físico-química. Os resultados foram submetidos à análise de variância (ANOVA) e teste de Tukey, ao nível de erro de 5\% [10].

A avaliação microbiológica foi realizada segundo a metodologia de amostragem e diluição das amostras recomendada pela AMERICAN PUBLIC HEALTH ASSOCIATION [1]. Os microrganismos indicadores, coliformes totais e coliformes fecais, foram enumerados pelo método do Número Mais Provável (NMP). Na contagem de bolores e leveduras utilizou-se o método de plaqueamento direto das diluições, segundo INTERNACIONAL COMISSION ON MICROBIOLOGICAL SPECIFICATIONS FOR FOODS [12].

\section{3 - RESULTADOS E DISCUSSÂO}

Os resultados médios obtidos nas determinações físico-químicas da matéria-prima estão apresentados na Tabela 1.

A Tabela 2 apresenta os resultados obtidos na avaliação sensorial para os atributos de aparência, cor, aroma, sabor e textura dos sorvetes de frutos dos cinco genótipos de mamão.

TABELA 1. Resultados médios das determinações físicoquímicas dos frutos de cinco genótipos do Banco Ativo de Germoplasma de Mamão da EMBRAPA-CNPMF, Cruz das Almas, Bahia.

\begin{tabular}{lcccccccccc}
\hline & \multicolumn{10}{c}{ Determinações } \\
\cline { 2 - 11 } Genótipos & pH & ATT & SS & "RATIO" & AA & ST & CINZAS & AR & ANR & AT \\
& & (gáccitr/100g) & $\left({ }^{\circ}\right.$ Brix $)$ & & (mg/100g) & $(\%)$ & $(\%)$ & $(\%)$ & $(\%)$ & $(\%)$ \\
\hline CMF012 & 5,32 & 0,13 & 14,0 & 112,44 & 84,0 & 9,50 & 0,30 & 11,3 & 0,6 & 11,9 \\
CMF020 & 5,17 & 0,12 & 13,6 & 113,72 & 89,8 & 14,40 & 0,23 & 10,9 & 0,9 & 11,8 \\
CMF023 & 4,94 & 0,16 & 11,0 & 68,26 & 93,0 & 13,50 & 0,40 & 9,5 & 0,5 & 10,0 \\
CMF031 & 5,38 & 0,09 & 14,0 & 152,07 & 68,0 & 13,30 & 0,26 & 9,8 & 0,6 & 10,4 \\
CMF047 & 5,28 & 0,07 & 12,6 & 173,41 & 54,7 & 14,70 & 0,42 & 10,1 & 0,8 & 10,9 \\
\hline
\end{tabular}

ATT: Acidez Total Titulável; SS: Sólidos Solúveis; “Ratio”:SS/ATT; AA:Ácido Ascórbico; Ar:Açúcar Redutor; ST:Sólidos Totais; ANR:Açúcar Não Redutor; AT:Açúcar Total.
Médias de cinco amostras.

TABELA 2. Resultados médios da avaliação sensorial dos sorvetes de frutos de cinco genótipos do Banco Ativo de Germoplasma de Mamão da EMBRAPA-CNPMF, Cruz das Almas, Bahia.

\begin{tabular}{lccccc}
\hline \multirow{2}{*}{ Genótipos } & \multicolumn{5}{c}{ Atributos } \\
\cline { 2 - 6 } & Aparência & Cor & Aroma & Sabor & Textura \\
\hline CMF012 & $7,00 \mathrm{a}$ & $7,23 \mathrm{a}$ & $7,47 \mathrm{ab}$ & $7,17 \mathrm{~b}$ & $7,43 \mathrm{a}$ \\
CMF020 & $7,27 \mathrm{a}$ & $7,33 \mathrm{a}$ & $7,17 \mathrm{ab}$ & $7,73 \mathrm{ab}$ & $7,97 \mathrm{a}$ \\
CMF023 & $7,23 \mathrm{a}$ & $7,40 \mathrm{a}$ & $6,97 \mathrm{~b}$ & $7,20 \mathrm{~b}$ & $7,20 \mathrm{a}$ \\
CMF031 & $7,50 \mathrm{a}$ & $7,50 \mathrm{a}$ & $7,57 \mathrm{a}$ & $8,13 \mathrm{a}$ & $7,80 \mathrm{a}$ \\
CMF047 & $7,57 \mathrm{a}$ & $7,37 \mathrm{a}$ & $7,17 \mathrm{ab}$ & $7,30 \mathrm{~b}$ & $7,80 \mathrm{a}$ \\
D.M.S. ${ }^{(1)}$ & 0,76 & 0,71 & 0,59 & 0,72 & 0,78 \\
C.V.. ${ }^{(2)}(\%)$ & 14,53 & 13,48 & 11,40 & 13,38 & 14,28 \\
\hline
\end{tabular}

Numa mesma coluna, médias com letra em comum não diferem significativamente (1) D si $(\mathrm{p}<0,05)$.

D.M.S.: Diferença mínima significativa do teste de Tukey ao nível de erro de $5 \%$. ${ }^{22)}$ C.V.: Coeficiente de variação.

Em relação a aparência e cor, os sorvetes alcançaram médias correspondentes aos termos da escala hedônica "gostei moderadamente", mostrando uma elevada aceitação dos produtos e não apresentaram diferença significativa $(\mathrm{p}<0,05)$ entre si. Para os provadores não houve prevalência entre os produtos, quanto à aparência e cor. Este resultado é particularmente interessante, pois qualquer diferença que os genótipos apresentaram na aparência da fruta in natura desapareceu no produto processado e o sorvete preparado com o genótipo CMF047, que apresenta coloração amarelo claro, destoou da cor dos demais produtos que eram vermelho-alaranjado claro. No entanto não houve rejeição do produto devido a sua cor. Pode-se afirmar que os genótipos de coloração amarela e aparência global pouco atraentes como frutos de mesa, poderão ser aproveitados na indústria para elaboração de produtos como o sorvete.

Quanto ao aroma, os provadores preferiram o aroma dos sorvetes preparados com os genótipos CMF012, CMF020, CMF031 e CMF047. Entretanto, observa-se que todos os sorvetes dos diferentes genótipos apresentaram adequada aceitação sensorial com relação a este atributo.

O sorvete processado com o genótipo CMF031 se destacou quanto ao seu sabor. Alcançou média correspondente a "gostei muito" e diferiu significativamente 
$(\mathrm{p}<0,05)$ dos sorvetes preparados com os genótipos CMF012, CMF023 e CMF047. Para os provadores, os sorvetes preparados com os genótipos CMF031 e CMF020 são os preferidos diante dos demais genótipos. Entretanto, observa-se que todos os sorvetes dos diferentes genótipos apresentaram adequada aceitação sensorial com relação ao sabor, com médias superiores a 7 .

Quanto à textura, os sorvetes preparados com os frutos dos cinco genótipos alcançaram médias correspondentes aos termos da escala hedônica entre "gostei moderadamente" e "gostei muito" e não apresentaram diferença significativa $(\mathrm{p}<0,05)$ entre si. Estes valores mostram uma elevada aceitação dos produtos quanto a este atributo. Os provadores não detectaram diferença na textura dos sorvetes em estudo; embora nos frutos in natura de alguns genótipos ocorreu a presença de fibras; porém, não influenciou na textura do sorvete, ou seja, a textura dos frutos in natura não influenciou na textura do produto processado.

As Tabelas 3 e 4 apresentam os resultados médios da composição centesimal e de outras determinações físico-químicas dos sorvetes dos frutos dos cinco genótipos de mamão.

Os sorvetes de fruta, por serem uma mistura de diversos alimentos de alta qualidade (leite, frutas, açúcares, etc.) que reúne todos os valores nutritivos desses ingredientes, são considerados como fontes de proteínas de alto valor biológico, pois têm todos os aminoácidos essenciais. Possuem vitaminas de todos os tipos, tanto as solúveis em água, provenientes da polpa das frutas naturais, como as solúveis em gordura, encontradas no leite [15]. Neste estudo, para os sorvetes dos frutos dos cinco genótipos de mamão, foram encontrados valores razoáveis de proteínas (cerca de 1\%).

Os sorvetes são ricos em diversos sais minerais (cálcio, sódio, potássio, magnésio, etc.) devido à presença do leite e da polpa de fruta [15]. Para os sorvetes de mamão foram encontrados valores na faixa de 0,50 0,33\% para cinzas.

Quanto aos lipídios, os valores foram reduzidos, variando de 0,30 a 0,60\%, não aumentando o valor calórico deste alimento.

TABELA 3. Resultados médios da composição centesimal dos sorvetes de frutos de cinco genótipos do Banco Ativo de Germoplasma de Mamão da EMBRAPA-CNPMF, Cruz das Almas, Bahia.

\begin{tabular}{lccccc}
\hline & \multicolumn{5}{c}{ Determinações } \\
\cline { 2 - 6 } Genótipos & $\begin{array}{c}\text { Umidade } \\
\%\end{array}$ & $\begin{array}{c}\text { Proteínas } \\
\%\end{array}$ & $\begin{array}{c}\text { Lipídeos } \\
\%\end{array}$ & $\begin{array}{c}\text { Cinzas } \\
\%\end{array}$ & $\begin{array}{c}\text { Carboidratos } \\
\%\end{array}$ \\
\hline CMF012 & $66,18 \mathrm{~d}$ & $1,08 \mathrm{a}$ & $0,63 \mathrm{a}$ & $0,51 \mathrm{a}$ & 31,60 \\
CMF020 & $69,18 \mathrm{a}$ & $1,06 \mathrm{a}$ & $0,47 \mathrm{~b}$ & $0,42 \mathrm{bc}$ & 28,87 \\
CMF023 & $65,18 \mathrm{e}$ & $1,12 \mathrm{a}$ & $0,27 \mathrm{~d}$ & $0,45 \mathrm{ab}$ & 32,98 \\
CMF031 & $67,96 \mathrm{c}$ & $0,96 \mathrm{~b}$ & $0,28 \mathrm{~cd}$ & $0,33 \mathrm{~d}$ & 30,47 \\
CMF047 & $68,78 \mathrm{~b}$ & $0,95 \mathrm{~b}$ & $0,33 \mathrm{c}$ & $0,38 \mathrm{~cd}$ & 29,56 \\
D.M.S. $^{(1)}$ & 0,01 & 0,09 & 0,054 & 0,06 & - \\
C.V. $^{(2)}{ }^{(\%)}$ & 0,17 & 4,41 & 7,14 & 7,82 & - \\
\hline
\end{tabular}

Numa mesma coluna, médias com letra em comum não diferem significativamente

entre si ( $\mathrm{p}<0,05)$.
(1) D.M.S. Diferenca minima significativa do teste de Tukey ao nivel de erro de $5 \%$. (2) C.V.: Coeficiente de variação.
Os dados da Tabela 4 revelam que, em relação às determinações de $\mathrm{pH}$ e acidez total titulável, os sorvetes apresentaram valores bem próximos do mamão in natura (Tabela 1), com uma ligeira elevação nos valores de $\mathrm{pH}$, sendo estes valores esperados para o produto, devido à adição do leite.

TABELA 4. Resultados médios das determinações físicoquímicas dos sorvetes de frutos de cinco genótipos do Banco Ativo de Germoplasma de Mamão da EMBRAPACNPMF, Cruz das Almas, Bahia.

\begin{tabular}{|c|c|c|c|c|c|c|c|c|c|}
\hline \multirow[b]{2}{*}{ Genótipos } & \multicolumn{7}{|c|}{ Determinaçōes } & \multirow[b]{2}{*}{$\begin{array}{l}\text { ANR } \\
(\%)\end{array}$} & \multirow[b]{2}{*}{$\begin{array}{l}\text { AT } \\
(\%)\end{array}$} \\
\hline & $\mathrm{pH}$ & $\begin{array}{c}\text { SS } \\
\left({ }^{(} \mathrm{B} \text { rix }\right)\end{array}$ & $\begin{array}{c}\text { ATT } \\
\text { (gác.citrico/100g }\end{array}$ & "RATIO" & $\begin{array}{c}\mathrm{AA} \\
(\mathrm{mg} / 100 \mathrm{~g})\end{array}$ & $\begin{array}{l}\text { ST } \\
(\%)\end{array}$ & $\begin{array}{l}\text { AR } \\
(\%)\end{array}$ & & \\
\hline CMF012 & $5,53 \mathrm{c}$ & $32,8 \mathrm{a}$ & $0,12 \mathrm{a}$ & $275,00 a b$ & $22,3 \mathrm{c}$ & $33,82 \mathrm{~b}$ & $22,3 \mathrm{a}$ & $4,8 a$ & $27,1 \mathrm{a}$ \\
\hline CMF020 & $5,87 \mathrm{a}$ & $30,2 \mathrm{c}$ & $0,12 a$ & $259,09 b$ & $40,0 \mathrm{ab}$ & $30,82 \mathrm{e}$ & 23,1 a & $2,8 \mathrm{~b}$ & $25,9 c$ \\
\hline CMF023 & $5,69 \mathrm{~b}$ & $33,2 \mathrm{a}$ & $0,13 \mathrm{~b}$ & $262,31 b$ & $49,0 \mathrm{a}$ & $34,82 \mathrm{a}$ & $22,9 \mathrm{a}$ & $3,7 \mathrm{ab}$ & b $26,6 \mathrm{~b}$ \\
\hline CMF031 & $5,72 \mathrm{~b}$ & $31,2 \mathrm{~b}$ & $0,11 \mathrm{c}$ & $293,09 a$ & $41,4 \mathrm{a}$ & $32,04 \mathrm{c}$ & 22,2 a & $4,2 \mathrm{a}$ & $26,4 \mathrm{~b}$ \\
\hline CMF047 & $5,67 \mathrm{~b}$ & $30,8 \mathrm{bc}$ & $0,11 \mathrm{c}$ & $293,09 a$ & $30,0 \mathrm{bc}$ & $31,22 \mathrm{~d}$ & 22,8 a & $4,4 a$ & $27,2 \mathrm{a}$ \\
\hline D.M.S. ${ }^{(1)}$ & 0,12 & 0,85 & 0,009 & 23,52 & 10,52 & 0,01 & 1,21 & 1,29 & 0,39 \\
\hline C.V.. ${ }^{(2)}(\%)$ & 1,09 & 1,41 & 4,27 & 4,48 & 15,21 & 0,17 & 2,80 & 17,12 & 9,78 \\
\hline
\end{tabular}

SS: Sólidos Solúveis; ATT: Acidez Total Titulável; Ratio: SS/ATT; AA: Ácido Ascórbico;

ST: Sólidos Totais;
AR: Açúcar Redutor; ANR: Açúcar Não Redutor; AT: Açúcar Total

Médias de cinco amostras.

Numa mesma coluna, médias com letra em comum não diferem significativamente entre si (p<0,05). (1) D.M.S.: Diferença mínima significativa do teste de Tukey ao nivel de erro de $5 \%$.
(2) C.V Coeficiente de variação.

O sorvete do genótipo CMF031 apresentou valor elevado de "ratio", sólidos solúveis acima de $31^{\circ}$ Brix e alcançou a maior média para o atributo sabor.

O balanço entre os conteúdos de ácidos orgânicos e os de açúcares exercem importante contribuição para a qualidade do sabor; embora, o nível de ácidos orgânicos encontrado nos sorvetes de mamão seja notadamente baixo, o alto teor de açúcares encontrado, atribuiu um sabor agradável ao produto. Os valores de sólidos solúveis ( $\left.{ }^{\circ} \mathrm{Brix}\right)$ encontrados nos sorvetes se aproximam dos valores de carboidratos totais $(30,0$ a $32,0 \%)$.

Os valores de ácido ascórbico foram aproximadamente $50 \%$ dos valores encontrados para a fruta in natura (Tabela 1). Considerando as devidas proporções de polpa de mamão utilizadas na formulação do sorvete, pode-se afirmar que não houve perda desta vitamina no produto final, devido ao processamento. Os teores de vitamina C (ao redor 40,0mg/100g) praticamente supre as necessidades diárias dessa vitamina para uma pessoa adulta, que deve ser de 30,0 a 75,0mg [9].

TABELA 5. Resultados das análises microbiológicas realizadas nas amostras de sorvete de mamão

\begin{tabular}{lcc}
\hline \multicolumn{1}{c}{ Análises } & Resultados/grama $\left(^{*}\right)$ & Padrão/grama \\
\hline Coliformes totais (NMP/g) ${ }^{\#}$ & $<3,0$ & - \\
Coliformes fecais (NMP/g) & $<3,0$ & - \\
E. Coli (confirmativo) & $(-)$ & - \\
Bolores e Leveduras (UFC/g) ${ }^{*}$ & $<10$ & - \\
\hline
\end{tabular}

(*) Resultados médios de cinco amostras.

() $\mathrm{UFC} / \mathrm{g}$ - unidades formadoras de colônias por grama. 
A Tabela 5 apresenta os resultados das contagens de microrganismos analisados nas amostras de sorvete. Examinando-se estes dados, verifica-se que as contagens de bolores e leveduras, assim como, das bactérias coliformes totais e fecais tiveram resultado satisfatório, pois obedeceram aos padrões estabelecidos pela Portaria 451 de 19/09/97 do Ministério da Saúde para produtos gelados [5].

\section{4 - CONCLUSÕES}

- Os sorvetes dos frutos dos cinco genótipos selecionados demonstraram elevada aceitação para todos os atributos avaliados.

- Os sorvetes dos frutos dos genótipos CMF020 e CMF031 obtiveram maior aceitação dos provadores, para o atributo sabor.

- Não houve prevalência entre os produtos quanto à textura, cor e aparência, indicando que os genótipos pouco atraentes como fruto de mesa, poderão ser aproveitados na indústria para elaboração de sorvete.

- Os sorvetes apresentaram razoáveis teores de proteínas, vitamina $\mathrm{C}$ e carboidratos.

- O sorvete de mamão é, portanto, uma excelente alternativa para aproveitamento da fruta.

\section{5 - REFERÊNCIAS BIBLIOGRÁFICAS}

[1] AMERICAN PUBLIC HEALTH ASSOCIATION. 1984. Standart methods for the examination of dairy products. 13.ed., Washington D.C., $416 \mathrm{p}$

[2] AOAC - ASSOCIATION OF OFFICIAL ANALYTICAL CHEMISTS. 1995. Official methods of analysis. 16 ed., Arlington, 1141 p.

[3] ARRIOLA, M. C.; CALZADA, J.F.; MENCHU, J.F.; ROLZ, C.; GARCIA, R. 1980. Papaya. In: Tropical and subtropical fruits. Westport: AVI, p. 316-340.

[4] BLEINROTH, E.W.; SIGRIST, J.M.M. 1995. Matéria-prima. In: MEDINA, J. C. editor. Mamão: cultura, matéria-prima, processamento e aspectos econômicos. Campinas: ITAL, p. 179-254. (Frutas tropicais, 7).

[5] BRASIL. Ministério da Saúde. Secretária Nacional de Vigilância Sanitária. Portaria $n^{\circ} 451$, de 19 de setembro de 1997. Dispõe sobre padrões microbiológicos. Diário Oficial da República Federativa do Brasil. Brasília, DF, 02 jul. 1998, Seção I, p 48.

[6] DE MARTIN, Z.J.; OLIVEIRA, N.de; KATO, K.; GALEB, S.E.A.; SILVA, S.D.; LAZZARINE, V. Descascamento mecânico do mamão e processamento do purê asséptico. Coletânea do Inst. Tecnologia de Alimentos, Campinas, v. 8 , n. 1 , p. 409-436. 1977.
[7] DE MARTIN, Z.J.; TEIXEIRA, C.G.; BLEINORTH, E.W.; ANGELUCCI, E.; PUPO, L.M.; TOSELLO, Y. Processamento de purê de mamão pasteurizado. Coletânea do Instituto de Tecnologia de Alimentos, Campinas, v. 4, n. 1, p. 155-176. 1971/72.

[8] DRAETTA, I.S.; SHIMOKOMAKI, M.; YOKOMIZO, Y.; FUJITA, J.T.; MENEZES, H.C.de; BLEINORTH, E.W. Transformações bioquímicas do mamão (Carica papaya) durante a maturação. Coletânea do Inst de Tecnologia de Alimentos, Campinas, v. 6, n. 1, p. 395-408. 1975.

[9] DUCKWORTH, R. B. 1988. Frutas y verduras. Zaragoza: Acribia. $304 \mathrm{p}$

[10] GOMES, F. P. 1990. Curso de estatística experimental. 13 ed, São Paulo: Nobel. 468 p.

[11] INSTITUTO ADOLFO LUTZ. Normas Analíticas do Instituto Adolfo Lutz: métodos químicos e físicos para análise de alimentos. 3 ed., São Paulo, v. 1. 1985.

[12] INTERNATIONAL COMISSION ON MICROBIOLOGICAL SPECIFICATIONS FOR FOODS. 1978. Microrganisms in foods: 1. their significance and methods of enumeration, 2 ed. Toronto: University of Toronto Press. 433 p.

[13] MACFIE, H.J.; BRATCHELL, N. 1989. Designs to balance the effect of order of presentation and first-order carry-over effects in hall tests. Journal of Sensory Studies, Connecticut, 4 ( Aug): 129-148.

[14] MADISON CONSUlTORES. 1998. Processo semi-industrial com uso de pasteurizador. Sorvetes 2000, São Paulo. (Curso intermediário de produção de sorvetes). v. 3, n. 14, p. 9-12. 1998.

[15] MADRID, A.; CENZANO, I.; VICENTE, J.M. 1996. Manual de indústrias dos alimentos. São Paulo: Livraria Varela. 599 p.

[16] MONTEIRO, C.L.B. 1984. Técnicas de avaliação sensorial. 2.ed. Curitiba: CEPPA-UFPR. 30 p.

[17] PÁDUA, T. Fisiologia pós-colheita, maturação controlada e armazenamento do mamão. Informe Agropecuário, Belo Horizonte, v. 12, n. 134, p. 59-61. 1986.

[18] PANTASTICO, E.B. et al. 1975. Postharvest physiology, handling and utilization of tropical fruits and vegetables. Westport: AVI, p. 339-362.

[19] SANTANA, L.R.R. Avaliação sensorial, físico-química e industrial de frutos de genótipos melhorados de mamão (Carica papaya L) 2001. 127 p., Mestrado em Ciências Agrárias, Escola de Agronomia, Universidade Federal da Bahia, Brasil (UFBa)

[20] SOLER, M.P.; DE MARTIN, Z.J.; FERNANDES, M.H.C.; MORI, E.E.M.; FERREIRA, V.L.P. Influência dos processos de descascamento na qualidade do purê de mamão da variedade Solo. Boletim do Instituto de Tecnologia de Alimentos, Campinas, v. 22, n. 1, p. 107$123,1985$.

[21] TEIXEIRA, E.; MEINERT, E.M.; BERBETTA, P.A. Análise sensorial de alimentos. Florianópolis: Universidade Federal de Santa Catarina. 1987, 180p. 